\title{
Climate Change Policy: A Theorist's Plea to Take Heed of Game Theory and Ambiguity Aversion
}

\section{José A. Rodrigues-Neto ${ }^{1}$}

How fast and to what extent should Australia cut its emissions? Agenda 14(3) presented a Symposium on Climate Change that aired the existing division of opinions. ${ }^{2}$ Some argued that we need to undertake large cuts now, while others have been much more sceptical about the severity of the impacts that temperature change might bring. Despite such divisions, it would seem most analysts would subscribe to the proposition that we need 'to balance costs and benefits of proposed policies'. Indeed, at present, the debate implicitly assumes that we can make a straightforward cost-benefit analysis, the only potential problem being the one of obtaining good quantitative measures for the relevant variables.

We argue that this view is incomplete, if not incorrect, and may bring disastrous outcomes in one way or another. Here, we claim that the design of optimal policies may not be as simple as one would think at first glance.

We contend that the discussion about the theoretical framework Australian economists are using to model climate-change-related policies has been greatly lacking. In this regard, we claim that decision theory and game theory should be among the top priorities.

Is it a good idea to use standard expected-utility theory to do a cost-benefit analysis? We do not think so. If researchers choose to use theoretical models that incorporate ambiguity aversion, as we suggest, the literature presents some alternatives. ${ }^{3}$ There are several questions that must be answered. For instance, how can we construct aggregate measures of risk and ambiguity aversion representing all Australians? How much of public resources, if any, must the government spend in order to protect us from the worst outcomes generated by

1 School of Economics, College of Business and Economics, Australian National University, jose.neto@anu.edu.au. I would like to thank William Coleman and two anonymous referees for valuable comments. All remaining mistakes are my own responsibility.

2 See McKibbin (2007a) and (2007b); Quiggin (2007a) and (2007b); as well as Robson (2007a) and (2007b).

3 Ellsberg (1961) presented a famous experiment in which most subjects act in violation of expectedutility theory's predictions. The violation is sometimes explained by the existence of ambiguity aversion: that people prefer to bet (even if they have to pay a small premium) on an urn with 50 red and 50 blue balls, than in one with 100 balls but where the number of each colour is unknown. Ghirardato et al. (2004) and Marinacci (2000) have theoretic foundations for a decision theory and game theory that incorporates ambiguity aversion. See Potamites and Zhang (2007), as well as Zhang (2007) and the references there for empirical evidence suggesting that there is some positive degree of ambiguity aversion on the behaviour of subjects in a controlled experiment, and for quantitative estimation of ambiguity aversion measures. 
the lotteries associated with policies related to climate change? To try to answer these we need to know first how much we will spend in research and which areas need priority.

Further, for each fixed proposed policy, how certain are we about the outcomes that climate change may bring? As Knight (1921) taught us, there is a subtle but important difference between risk and uncertainty. The concept of risk is related to the fact that decision-makers obtain stochastic outcomes for their choices. For instance, when we flip a coin we do not know which side will come up next, but we are pretty sure that each side has a 50 per cent chance of coming up. On the other hand, the idea of uncertainty suggests that there is less-than-perfect confidence over the probabilities associated with some actions. For instance, what is the probability that we will find ourselves in a catastrophic situation 50 years from now if we do not cut emissions at all? One expert may say it is 'around 20 per cent', while another, equally respected, scientist may answer that 'it is at least 60 per cent'. Not only the consequences of 'doing nothing' are uncertain, but the mere assignment of probabilities to possible outcomes is a complicated task. As Weitzman (2007) explains in his critique of the famous Stern Review, when it comes to the assignment of discount rates in Climate Change models 'uncertainty tends to matter much more than risk'.

This time scientists cannot rely on the expected-utility theory as usually applied by economists because the challenges ahead of us involve a considerable amount of risk and uncertainty and also complex strategic considerations. We do not know every possible scenario that may happen. Even if we could list them all, we still would not know the real probabilities associated with each possible policy. Any estimate would be just a guess because natural scientists still work in many open problems. Besides, there is also a large source of uncertainty associated with other countries' policies. Even if we knew exactly how pollution outcomes were translated into temperature changes, we would still not understand how seriously other governments would deal with the issue, or how cooperative they would be. After all, typically politicians play to their own home audience.

Furthermore, we need to explicitly differentiate the uncertainty regarding natural outcomes from the 'strategic uncertainty', which is brought upon us due to the fact that we are playing a strategic game with other countries. The climate change problem that Australia is confronting today is part of a game because every country's actions impact everybody else. The strategic nature of this problem might have been overlooked so far. The best strategy we can play is a function of other players' strategies, which themselves depend on their opponents' strategies, and so on.

4 Stern (2006) is a report about climate change officially commissioned by the British government in 2005. 
The repeated nature of the players' interaction is very important. The literature points out that agents playing repeated games may obtain, on average, much better outcomes than they would in a static environment, if they are sufficiently patient. This kind of result is usually known as a 'folk theorem'. In a long, repeated strategic interaction it is possible to create incentives for cooperation by punishing, or threatening to punish, deviators. To formulate an optimal strategy one needs to design a contingent plan of action for every history of action profiles that all nations have played. In other words, our plan must be quite flexible and prescribe our actions under many different circumstances.

Unfortunately, however, the theories of dynamic games and repeated games with incomplete information are still unfinished. There are many open questions and more research is needed. In particular, the theory of dynamic stochastic games is not well developed. Studying climate change with this tool may be the best way to develop critical insights and to design sensible policies, but few research papers use this analytical framework. ${ }^{5}$

Nevertheless, game theory is the most reasonable framework to date for dealing with the strategic and repeated interaction of many governments when they all face uncertainty. For instance, any Nash equilibrium of a repeated game always explicitly describes what are the possible punishments players may face and the incentives that other players have to carry out each prescribed punishment. In other words, all nations have the incentive to keep to the equilibrium path, and, if a country is called upon to punish a deviator, it will in fact have sufficient long-run incentive to carry on the punishment even if this means short-run losses. In sum, the concepts of Nash equilibrium and sub-game perfect equilibrium are based on credible threats.

What level of international cooperation is likely to occur in practice? Does Australia need to have a direct benefit to reduce its emissions, given that we are not a major polluter? Is there a 'first move' advantage in this game or is it just silly to cut emissions now before others commit themselves to a long-run agreement?

Making a first move in cutting emissions is costly in the short run, but it could place us in a more favourable position in the future. There are at least three different reasons for this. First, it may smooth consumption, allowing internal agents to adjust more gradually to cleaner technologies. Second, it provides incentives for Australian scientists and technicians to take the lead in this research area. Third, it establishes our international reputation as a leader in the field, both in the policy area and in scientific and technological

\footnotetext{
5 The lack of research on climate change with up-to-date decision theoretical and game theoretical tools is not only a problem for Australia. To the best of our knowledge, there is no climate change model that simultaneously incorporates the recent findings of research in ambiguity aversion and stochastic dynamic game theory. We thank an anonymous referee for bringing this point to our attention.
} 
development. There is an extensive literature on the value of reputation and on reputation-building. ${ }^{6}$

The Howard government was criticised for not signing the Kyoto Protocol. Has Australia lost the initiative and reputation when it comes to climate change? If so, how bad is this for future agreements? Solid scientific answers are likely to require the use of sophisticated game theory. In particular, the theory of repeated games with incomplete information seems to be necessary. In any event, it is wise for Australia to actively participate in the international debate because climate change may impact our country even if our own direct actions turn out to have little or insignificant direct impact. If we understand the situation well, we may help in the design of international agreements, efficient policies and new technologies that may change everybody's future.

Sceptics such as Alex Robson claim that Australia is a minor polluter and that huge sacrifices may not have a significant impact on the global situation. 7 Even if this is true, Australia may be punished by other countries if we do not adhere to major international agreements. It does not seem wise to count on free riding on other countries' emissions cuts. A dynamic decision theoretic approach must be established. Being flexible with any possible numerical target does not mean that Australia has a weak attitude towards climate change. The important point is that we must be capable of using the most recent and accurate scientific information and technologies available. Such information and new technologies will come from future developments in both natural and social sciences.

Game theory has been criticised for not working with quantitative questions. In fact, it is a relatively common mistake to consider quantitative results as being of more use or of having more applicability then qualitative results. ${ }^{8}$ We argue that more important than knowing the exact numbers of the reduction in emissions and their costs, the very nature of desirable equilibria must be established first. How often are emissions going to be measured and what, if any, structure of punishments will be capable of enforcing optimal equilibrium? How complex will the strategies need to be? Is it a good idea to have a single round of 'hard' punishments for deviators or are longer 'soft' punishments more

\footnotetext{
${ }^{6}$ For some of the most recent references, see Cripps et al. (2004), Mailath and Samuelson (2006) and Ely et al. (2008).

7 See Robson (2007a).

${ }^{8}$ It is not hard to see scientists who use alternative approaches to study Climate Change criticising game theory for different reasons. Typically, they make unfair claims and work with a variety of alternatives such as optimal control theory, purely empirical studies or general equilibrium models. We regard most of these criticisms as a natural outcome in an environment where scientists are highly specialised and there is intense competition for research funds and academic prestige. These alternative techniques usually miss important and complex elements of the question because they do not focus on the strategic nature of the problem. The fact that several pure and applied game theorists have recently won Nobel Prizes is a good indication of the power and potential of this field.
} 
effective? Before addressing these qualitative issues, very specific quantitative questions are unlikely to get realistic answers.

How will we deal with disputes in the measurements? Again, game theory may save the day. Imperfect monitoring is also explicitly studied by the theory of repeated games. ${ }^{9}$ The good news here is that the literature has some results indicating that much of the structure of folk theorems is saved, with some technical adjustments, when one introduces imperfect monitoring.

Certainly, it is costly to invest in research. Game theory is an abstract, hard, highly mathematised discipline. But it may turn out to be much more costly for Australians not to invest in this field. Without explicitly incorporating these two elements into the discussion - namely, ambiguity aversion and the strategic and repeated nature of the nations' interaction - much of the argument will be circular, or based on individual preferences or attitude towards risk and uncertainty. The debate will continue to be rich in factual knowledge, but poor on strategic reasoning. The sooner the discussion in Australia incorporates decision theoretic and game theoretic concepts, the correct tools for qualitative studies, the sooner social scientists will enter on the right track to attack problems related to climate change.

\section{References}

Cripps, M., Mailath, G. and Samuelson, L. 2004, 'Imperfect Monitoring and Impermanent Reputations', Econometrica 72: 407-32.

Ellsberg, D. 1961, 'Risk, ambiguity, and the Savage axioms', Quarterly Journal of Economics 75: 643-69.

Ely, J., Fudenberg, D. and Levine D. 2008, 'When is reputation bad?', Games and Economic Behavior, forthcoming.

Ghirardato, P., Maccheroni, F. and Marinacci, M. 2004, 'Differentiating ambiguity and ambiguity attitude', Journal of Economic Theory 118: 133-73.

Knight, F. H. 1921, Risks, Uncertainty, and Profit, Boston: Houghton-Mifflin.

Kreps, David M. 1988, Notes on the Theory of Choice, Underground Classics in Economics, Westview Press.

Mailath, G. and Samuelson, L. 2006, Repeated Games and Reputations: Long-run Relationships, Oxford University Press.

Marinacci, M. 2000, 'Ambiguous Games', Games and Economic Behavior 31: 191-219.

McKibbin, W. 2007a, 'The Prime Ministerial Task Group on Emissions Trading: An Assessment', Agenda 14(3): 13-7.

\footnotetext{
9 See Mailath and Samuelson (2006).
} 
McKibbin, W. 2007b, 'Reply to Quiggin and Robson', Ibid.: 29-30.

Potamites, E. and Zhang, B. 2007, 'Heterogeneous Ambiguity Aversion: a field experiment among small-scale stock investors in China,' working paper, at: http://beizhangbei.googlepages.com/BeiZhangPaper2.pdf

Quiggin, J. 2007a, 'The Prime Ministerial Task Group on Emissions Trading: Advocacy and Analysis'. Agenda 14(3): 5-12.

Quiggin, J. 2007b, 'Reply to McKibbin and Robson', Ibid.: 27-8.

Robson, A. 2007a, 'The Prime Ministerial Task Group on Emissions Trading: An Assessment' Agenda 14(3): 13-7.

Robson, A. 2007b, 'Reply to McKibbin and Quiggin', Ibid.: 31-2.

Stern, N. 2006, 'Stern Review on the economics of climate change' at: http://www.hm-treasury.gov.uk/independent_reviews/stern_review_economics_climate_change/stern_review_report.cfm

Weitzman, Martin L. 2007, 'A Review of the Stern Review on the Economics of Climate Change', Journal of Economic Literature 45(3): 703-24.

Zhang, B. 2007, 'Measuring Ambiguity Attitudes and Beliefs: an Experimental Study', working paper: http://beizhangbei.googlepages.com/BeiZhangPaper1.pdf 